https://doi.org/10.48009/1_iis_2008_146-151

\title{
STUDENT-BASED IT FOR NONPROFITS - AN ALTERNATIVE TO DO-IT-YOURSELF IT
}

\author{
Ted J. Strickland Jr., University of Louisville, ted.strickland@louisville.edu
}

\begin{abstract}
Among smaller nonprofit organizations, budget limits constrain IT investments and use. Many organizations rely on a combination of donated equipment, volunteers, and non-IT staff members to conduct large elements of their IT operations. The limitations of this "Do-It-Yourself" IT (DIY-IT) model make it less attractive as a long-term solution. An alternative model of providing IT services is proposed, in which nonprofit organizations receive IT services through undergraduate information systems course projects and the activities of sponsored students. The proposed model is designed to be more affordable, more standardized, and more sustainable than the current IT practices of many small to medium-sized nonprofit organizations.
\end{abstract}

Keywords: Do-It-Yourself IT, DIY-IT, Nonprofit IT, CIS Course Projects.

\section{INTRODUCTION}

For many nonprofit organizations, especially small to medium-sized ones, funding IT adequately and leveraging IT capabilities sufficiently are difficult activities. Executive directors and department managers who participated in undergraduate Computer Information Systems (CIS) course projects indicated that many aspects of IT acquisition, setup, operations, and support present budgeting and staffing challenges.

The executives' comments focused on the costs of IT. For most nonprofits, budgets were inadequate to provide needed IT capabilities at market rates. Solutions are innovative, including in-kind donations of hardware, reliance on volunteers for IT setup, designation of non-technical staff members for IT support, and investment of non-recurring funds (e.g., grants, designated donations) for upgrades and new IT projects. In addition to affordability issues, their comments conveyed a broader concern for how to plan for and how to use IT in improving their processes.

\section{THE STATE OF IT IN SMALLER NONPROFIT ORGANIZATIONS}

The nonprofit sector has established how many of its organizations perceive their IT capabilities and how they plan for and manage IT [2, 3,6]. Responses to similar questions from the 2001 Princeton survey [6] and from the recent survey conducted by Nonprofit Technology Network (NTEN) [2, 3] are summarized in Table 1. Concerns identified in 2001 are still issues seven years later. Overall, small and mediumsized nonprofits have not made progress in developing IT strategies or IT plans. Keeping pace with advances in IT also remains a challenge. In other areas, such as IT budgeting and IT staffing, results indicate that many small nonprofit organizations continue to struggle with funding and staffing issues.

Recent experiences of the CIS program with 19 nonprofit organizations that participated in undergraduate course projects are consistent with these trends. Informal conversations with executive directors and department managers indicated that:

- $\quad$ Two of 10 (20\%) had IT plans;

- Four of $12(33 \%)$ included IT spending in their annual budgets;

- Nine of 19 (47\%) reported some type of IT expense directly on their federal Form 990 filings.

The nonprofit sector has provided reports to assist its organizations with their IT operations. For example, CompuMentor's manual [1] for technical volunteers offers guidelines pertaining to volunteer use for IT operations. These include:

- Appropriate task characteristics: short-term, nonurgent, and limited scope.

- Number of computers: 15 is the limit for volunteer-based support.

- Examples of success stories: using volunteers to provide one-on-one software training with staff members, to evaluate web design/hosting proposals, to set up networks, and to assess the suitability of donated equipment. 
Table 1. Survey Findings: IT Practices and Concerns of Nonprofit Organizations

\begin{tabular}{|l|c|c|c|c|}
\hline \multirow{2}{*}{ IT Practice / Concern } & \multicolumn{2}{|c|}{ Princeton Survey (2001) } & \multicolumn{2}{c|}{$\mathbf{~ N T E N ~ S u r v e y ~ ( 2 0 0 8 ) ~}^{\mathbf{2}}$} \\
\cline { 2 - 5 } & $\begin{array}{c}\text { Small } \\
\text { Nonprofits }\end{array}$ & $\begin{array}{c}\text { Medium } \\
\text { Nonprofits }\end{array}$ & $\begin{array}{c}\text { Small } \\
\text { Nonprofits }\end{array}$ & $\begin{array}{c}\text { Medium } \\
\text { Nonprofits }\end{array}$ \\
\hline $\begin{array}{l}\text { No IT strategy / } \\
\text { No IT plan }\end{array}$ & $76 \%$ & $77 \%$ & $77 \%$ & $67 \%$ \\
\hline No IT budget & 3 & $64 \%$ & $\begin{array}{c}26 \% \\
17 \%\end{array}$ & $\begin{array}{c}6 \% \\
6 \% \\
12 \%\end{array}$ \\
\hline $\begin{array}{l}\text { Not keeping up with IT advances } \\
\text { / IT adoption }\end{array}$ & $36 \%$ & $27 \%$ & $47 \%$ & $35 \%$ \\
\hline $\begin{array}{l}\text { No one with official IT } \\
\text { responsibility }\end{array}$ & N/A & N/A & $44 \%$ & $18 \%$ \\
\hline $\begin{array}{l}\text { No IT staff, either full-time or } \\
\text { part-time }\end{array}$ & N/A & N/A & $40 \%$ & $13 \%$ \\
\hline No “full-time IT" staff member(s) & $96 \%$ & $95 \%$ & N/A & N/A \\
\hline
\end{tabular}

$1 \quad$ Small: annual budget less than $\$ 100,000$; Medium: annual budget between $\$ 100,000$ and $\$ 1,000,000$

2 Small: annual budget less than $\$ 500,000$; Medium: annual budget between $\$ 500,000$ and $\$ 3,000,000$

3 NTEN survey requested budget information for IT salaries, IT capital, and discretionary IT spending

Similarly, the Baring Foundation's report [12] of IT practices among 30 voluntary organizations in the United Kingdom provides recommendations regarding IT planning, budgeting, and management, as well as the use of volunteers. For instance, the report recommends that:

- The IT strategy is reviewed by the governing board every year.

- The annual budget includes IT equipment, software, and network needs, IT training, and major IT projects.

- $\quad$ Paid staff member(s) are used for IT support, and the use of volunteers for IT operations is avoided whenever possible.

Studies of IT use among nonprofit organizations have begun to emerge from the academic community. Vowels [13] investigated use of do-it-yourself IT (DIY-IT) in operating the web sites of nonprofit art organizations. Her initial study found that volunteers were the largest contributors to web site design (39\%) and web site maintenance (36\%), surpassing the contributions of paid staff members, paid consultants, and donated services. Vowel's study, and Mathieson's related work [4, 5] with voluntary organizations, recommended further study of volunteer use in IT operations. Formal guidelines regarding the role and use of volunteers would be helpful to nonprofit organizations, especially those that use volunteers as an element of DIY-IT.
The DIY-IT model is associated with the open source software movement, specifically the use of Linux. DIY-IT is attributed to Searls [9], who proposed that knowledgeable IT departments may use Linux as a viable operating system. In addition to the cost savings associated with software licensing, the organization may leverage the collective knowledge of the open source development community in providing higher quality solutions, over time, than those of software vendors. DIY-IT presumes that the IT staff has the knowledge and experience to install or customize the open-source tools to create the operational systems needed by the organization. Rapoza [8] noted that the organization must recognize which IT projects are do-it-yourself based on its IT skill base, and which ones should involve solutions from IT vendors or should be outsourced to IT consultants.

\section{LIMITATIONS OF DIY-IT}

For small to medium-sized nonprofits, two issues appear to be at the forefront of IT adoption: (1) how to acquire and use IT within limited budgets; and (2) how to improve organizational planning for IT, including annual budgeting for IT.

On initial examination, the DIY-IT model addresses the acquisition issue. A typical acquisition cycle for a small nonprofit organization is similar to the following scenario. 
- A corporate representative delivers several recently retired computers to the nonprofit organization as an in-kind donation.

- A member of board of directors, who has IT experience, assembles a team of volunteers to configure the computers and network.

- A member of the volunteer team downloads open-source software needed for network setup and operations.

- $\quad$ The volunteer team meets on a weekend to set up the network and to install software on all of the computers.

- The nonprofit staff arrives on Monday morning to find "newer" computers, with networking capabilities.

The advantages of this variation of DIY-IT are evident to the nonprofit's executive director: (1) no hardware cost; (2) no software licensing costs; and (3) no personnel costs for network setup. Minor costs for network cables and discounted application software (e.g., www.techsoup.org) are covered from the organization's contingency fund.

However, the disadvantages of DIY-IT are more subtle. The following questions occur to the executive director later:

- How current are the computers? Will they make us more productive? Should we have accepted them?

- Who will help us learn to use the network features? Who will help us with software questions?

- Who will resolve technical problems with the computers and the network?

The answers to these questions are not simple. From the surveys cited above, at least 40 percent of the smaller nonprofit organizations do not have a fulltime IT staff member to provide operational support. In many cases, a member of the nonprofit staff may assist with resolving IT questions occasionally. She relinquishes a portion of her normal responsibilities to take on the "accidental techie" role. For this scenario, the software upgrades require that she learn several new packages, taking additional time from her regular assignment. Alternatively, the volunteer who installed the network software offers to provide technical support, but he is only available after 5 p.m. during the work week and on the weekends. The executive director pauses - how much staff time will be lost waiting for the volunteer to resolve a problem that occurs on a Wednesday morning? She concludes that the costs hidden in DIY-IT impact her staff's productivity substantially, even though they do not correspond to line items in her annual budget.

Technically, this scenario is not an example of DIYIT. Based on Searls' premise, it fails an important condition - the IT knowledge and skills needed to use the network do not exist within the operational capabilities of organization; i.e., the permanent staff could not have performed the upgrade. The necessary IT knowledge and skills only existed within the extended organization (the board member and volunteers) on a temporary basis. When the volunteers left the facility, so did their IT knowledge and skills. Unless volunteers commit to supporting the operational needs in a responsive, timely manner, they should not be considered part of the DIY-IT knowledge and skill base. In the scenario, DIY-IT would have been viable only if permanent members of the organization's staff had the IT knowledge and skills to "do-it-themselves". The IT knowledge and skills required for IT support are important, and this element of DIY-IT is easily overlooked in the enthusiasm to upgrade to newer technologies.

Three options for acquiring and using IT are identified in the scenario. Options, including less affordable ones involving third party IT professionals, include:

- Hiring a permanent IT staff member, either fulltime or part-time.

- Appointing a permanent staff member from another area to manage IT operations; i.e., select the "accidental techie".

- Using volunteers, preferably only ones with IT knowledge and skills.

- $\quad$ Negotiating a service level agreement with an IT company to provide specified services.

- Hiring IT consultants to respond to issues on an “as needed” basis.

Several considerations, such as breadth and depth of IT knowledge and skills, extent of management controls, and affordability, are important in selecting the option that best fits a nonprofit organization. The relative advantages and disadvantages of these options, including each option's conformance with the DIY-IT model, are listed in Table 2.

Improving organizational planning for IT, including annual budgeting for IT, are complex issues. The lack of a CIO, who typically develops the IT vision, among the typical small or medium-sized nonprofit organizations is a likely contributor to current practices. Several of the executive directors who participated in CIS course projects were advocates 
Table 2. Options for Acquiring and Using IT

\begin{tabular}{|c|c|c|c|}
\hline Option & Advantages & Disadvantages & DIY-IT \\
\hline $\begin{array}{l}\text { Permanent IT } \\
\text { staff member }\end{array}$ & $\begin{array}{ll}\text { - } & \text { Formal IT preparation } \\
& \text { Timely responses to } \\
\text { - } & \text { Accoblems } \\
\text { - } & \text { More affordable per incident } \\
\end{array}$ & $\begin{array}{ll}\text { - } & \text { Limited breadth of IT } \\
\text { knowledge; rarely is an IT } \\
\text { professional skilled in all IT } \\
\text { areas } \\
\text { - Need replacement during } \\
\text { vacations, illnesses, etc. }\end{array}$ & $\begin{array}{l}\text { Yes, with } \\
\text { moderate IT } \\
\text { training }\end{array}$ \\
\hline $\begin{array}{l}\text { Permanent } \\
\text { staff member } \\
\text { from another } \\
\text { area: the } \\
\text { "accidental } \\
\text { techie" }\end{array}$ & $\begin{array}{ll}\text { - } & \text { Timely responses to } \\
& \text { problems } \\
\text { - } & \text { Accountable for actions } \\
\text { - } & \text { More affordable per incident }\end{array}$ & $\begin{array}{l}\text { - } \quad \text { Unlikely to have formal IT } \\
\text { preparation } \\
\text { - } \quad \text { Narrow breadth of IT } \\
\text { knowledge } \\
\text { - } \quad \begin{array}{l}\text { Displaced from “normal” } \\
\text { responsibilities }\end{array} \\
\text { - Need replacement during } \\
\text { vacations, illnesses, etc. }\end{array}$ & $\begin{array}{l}\text { Yes, with } \\
\text { extensive IT } \\
\text { training }\end{array}$ \\
\hline $\begin{array}{l}\text { Volunteer with } \\
\text { IT knowledge } \\
\text { and skills }\end{array}$ & $\begin{array}{ll} & \text { Likely to have formal IT } \\
\text { preparation } \\
\text { - } \\
\text { Wide breadth of IT } \\
\text { knowledge among volunteer } \\
\text { base } \\
\text { - }\end{array}$ & $\begin{array}{ll}\text { - } & \text { Untimely responses to issues } \\
\text { - } & \text { Limited time commitments } \\
\text { - } & \text { Hot accountable for actions } \\
& \text { High turnover likely }\end{array}$ & $\begin{array}{l}\text { Unlikely; } \\
\text { only with } \\
\text { thoughtful } \\
\text { planning and } \\
\text { coordination }\end{array}$ \\
\hline $\begin{array}{l}\text { Service level } \\
\text { agreement }\end{array}$ & $\begin{array}{ll}\text { - } & \text { Formal IT preparation } \\
\text { - } & \text { Timely responses to } \\
\text { - } & \text { problems } \\
\text { Accountable for actions }\end{array}$ & $\begin{array}{ll}- & \text { Limited breadth of IT } \\
\text { knowledge, depending on } \\
\text { service area(s) }\end{array}$ & No \\
\hline IT consultants & $\begin{array}{ll}\text { - } & \text { Formal IT preparation } \\
\text { - } & \text { Wide breadth of IT } \\
\text { knowledge } \\
\text { - } \\
\quad \text { Timely responses to } \\
\text { - } & \text { Acoblems } \\
\end{array}$ & - $\quad$ Less affordable per incident & No \\
\hline
\end{tabular}

for more extensive IT use, but they acknowledged that progress is compounded by their lack of technical knowledge and the attitudes of board members and staff members. Because of their complexities, these issues are not addressed in detail in this paper. However, they are mentioned briefly in the next section as requirements of an alternative approach to improving IT practices among small to medium-sized nonprofit organizations.

\section{AN ALTERNATIVE IT SOLUTION FOR NONPROFIT ORGANIZATIONS}

The motivation to develop an alternative model under which nonprofit organizations acquire and use IT originated from a member of the CIS Corporate Partner advisory board. He challenged the CIS faculty to redirect the program's course projects from corporate settings to nonprofit settings. His knowledge of the projects conduced in the program's systems analysis and design courses $[10,11]$ led him to speculate that CIS students would have dramatic impacts on the IT operations of small to mediumsized nonprofit organizations in the Louisville area.

The first objective of the proposal was to make IT affordable to nonprofit organizations; i.e., to address directly the costs of IT. During the fall and spring semesters, students enrolled in CIS courses would conduct IT projects such as web site enhancements, including web extensions of business processes, at no cost. During periods when classes would not be in session, including the summer term, sponsored students would provide IT support. Also, sponsored 
students would perform IT tasks that are not easily structured as course projects. In these two instances, students would be offered stipends or scholarships for providing IT support to participating nonprofit organizations. Additionally, faculty oversight of course projects and sponsored students would be required, especially during the initial stages of development. Thus, the proposal stipulated that participating organizations would pay for IT assistance, but that the rates would be affordable. An initial estimate indicated that rates would be one-third to one-half of market rates.

The second objective was to develop a set of IT services that would accommodate the needs of multiple small to medium-sized nonprofit organizations. This strategy would move the organization's IT operations towards standardized practice and best practices. In identifying and developing the IT services, guidelines and experiences of organizations such as NPower (www.npower.org) were used as benchmarks. A pyramid model of nonprofit IT needs [7] was adopted as a way of describing the anticipated IT services (Figure 1):

- An IT strategic assessment service would help the nonprofit organization align its IT plan with its organizational goals, mission, vision, and strategic plan. Also, this assessment would determine where the organization's IT practices fall on the pyramid of IT needs.
- An infrastructure support service would help the nonprofit organization maintain a stable and secure computing environment.

- A set of common solutions, based on web deployment, would provide applications needed for the nonprofit organization to conduct its business processes effectively and efficiently. In some cases, the common solutions may transform one or more of the organization's business processes.

The third objective was to provide a sustainable set of IT services to the nonprofit organizations. An application service provider (ASP) model is envisioned, where the university and IT partner companies would coordinate delivery of the services. A nonprofit organization would pay fees for services based on the recommendations of the IT strategic assessment. For example, some organizations would subscribe to the infrastructure support service, others would subscribe to one or more components of the commons solutions, and a few would subscribe to both services. Consolidating the services under an ASP model would address IT issues that challenge nonprofit organizations:

- $\quad$ Keeping up with IT advances would become less of a concern. IT services would be standardized, moved towards best practices, and upgraded periodically.

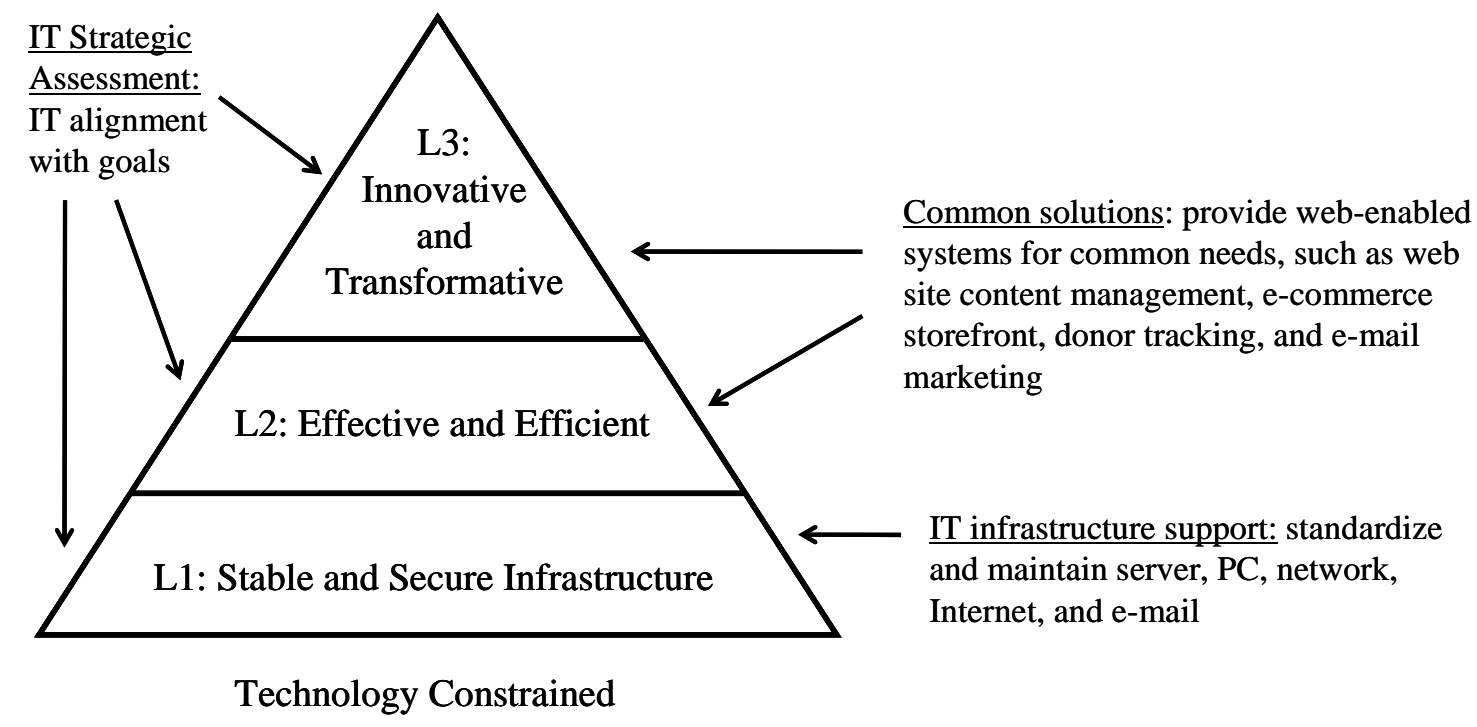

Figure 1. Pyramid of IT Needs and Proposed IT Services 
- In-kind donations of computing equipment would only be accepted if the equipment meets standards required for a stable and secure environment and if the equipment is capable of supporting effective and efficient operations.

- Issues associated with managing DIY-IT would be avoided, as IT staff members, "accidental techies", and/or volunteers would not be needed or their roles would be substantially reduced to performing nominal tasks.

Also, this model would address the organizational IT planning and IT budgeting concerns directly. A participating organization would be required to:

- Commit to budgeting for IT equipment and services, even in situations where the annual allocations to the IT budget increase incrementally from year to year.

- Develop an IT strategy as an element of participation in the IT strategic assessment service. The IT strategy would be expanded to form the organization's IT plan.

\section{CONCLUSIONS}

Acquiring, operating, and supporting IT continues to be a challenge for small to medium-sized nonprofit organizations. Use of DIY-IT lowers dramatically the costs of IT acquisition, but the hidden costs of operations and support should be considered carefully before adopting this model.

An alternative model that uses the knowledge and skills of information systems students, as course projects or sponsored assignments, would provide IT services that are more affordable than market rates, standardized and aimed at matching best practices, and sustainable using an ASP style of delivery through the university and its IT partner companies. The model requires that the nonprofit organization budgets for IT. Also, the model requires that the organization develop an IT strategy and/or plan. In this sense, the model addresses two of the larger IT issues facing smaller nonprofit organizations: (1) how to acquire and use IT within limited budgets; and (2) how to improve organizational planning for IT, including annual budgeting for IT.

\section{REFERENCES}

1. CompuMentor (2001). "Working with Technical Volunteers: A Manual for Nonprofit
Organizations”, San $\quad$ Francisco. http://www.techsoup.org/binaries/Files/TechVol Man2001v1.2.pdf

2. Levine, A. (2008). "Nonprofit IT Staffing: Staffing Levels, Recruiting, Retention and Outsourcing”, Nonprofit Technology Network, Portland, Oregon, January 29, 2008.

3. Levine, A. (2008). "Nonprofit IT Staffing: Budgets, Salaries, Training and Planning", Nonprofit Technology Network, Portland, Oregon, February 28, 2008. http://www.nptimes.com/technobuzz/07_NTEN_ ITStaffing_Part2.pdf

4. Mathieson, K. (2006). "Factors Influencing Intentions to Maintain Web Content in Voluntary Organizations”, ACM SIGMIS-CPR '06, pp. 169171, April 13-15, 2006.

5. Mathieson, K. (2006). "Using Volunteers for IT Work: Research Questions”, ACM SIGMIS-CPR '06, pp. 230-235, April 13-15, 2006.

6. Princeton Survey Research Associates (2001). "Wired, Willing, and Ready: Nonprofit Human Service Organization's Adoption of Information Technology”, summary report prepared for Independent Sector and Cisco Systems, December 2001. http://www.wkkf.org/Pubs/CCT/InfoCT/Wired Willing_Ready_00316_03178.pdf

7. Pyramid of IT Needs (2007). Conversation with Mike Harmon, CEO of NPower Indiana, June 28, 2007.

8. Rapoza, J. (2006). "The ABCs of DIY IT", eWeek, pg. 46, October 16, 2006.

9. Searls, D. (2004). "DIY-IT: How Linux and Open Source Are Bringing Do-It-Yourself to Information Technology”, Linux Journal, Issue 118, pp. 48-51, February 1, 2004.

10. Strickland, T.J., Jr. (2007). "Making OOA Real - Iterative and Incremental Projects", Issues in Information Systems, Vol. VIII(1):139-146.

11. Strickland, T.J., Jr. (2003). "Real Projects, Real Lessons - What Students Learn and What the Instructor Has Learned", Issues in Information Systems, Vol. IV(2):693-699.

12. Ticher, P., Maison, A., Jones, M. (2002). "Leading the Way to ICT Success", research report, Baring Foundation. http://www.baringfoundation.org.uk/ictsuccessne w.pdf

13. Vowels, S. (2005). "DIY-IT: An Empirical Study of Website Development Staffing by Nonprofit Organizations”, ACM SIGMIS-CPR '05, pp. 59-61, April 14-16, 2005. 